EPiC Series in Computing
Volume 52, 2018, Pages 301-315
$\begin{aligned} & \text { ICT4S2018. 5th International Conference on Informa- } \\ & \text { tion and Communication Technology for Sustainability }\end{aligned}$

\title{
Energy consumption of mobile data transfer - Increasing or decreasing? - Evaluating the impact of technology development \& user behavior
}

\author{
Hanna Pihkola, Mikko Hongisto, Olli Apilo, Mika Lasanen and Saija \\ Vatanen \\ VTT Technical Research Centre of Finland \\ hanna.pihkola@vtt.fi, mikko.hongisto@vtt.fi, olli.apilo@vtt.fi, \\ mika.lasanen@vtt.fi, saija.vatanen@vtt.fi
}

\begin{abstract}
Mobile data consumption in Finland is among the highest in the world. Increase in mobile data usage has been rapid and continuous growth is foreseen. While the energy consumed per transmitted gigabyte has substantially decreased, it seems that the absolute annual energy consumption related to mobile operators' activities has started to increase. Simultaneously, consumer behavior is changing. While new end-user devices are more and more energy-efficient, we use more and more time with mobile devices. Is increasing usage outweighing achieved energy savings? What kinds of options are available for tackling increasing energy demand?

This paper discusses current and future trends related to energy consumption of mobile data transfer and mobile networks in Finland. Using a top-down approach and publicly available data, an illustrative trend ( $\mathrm{kWh} /$ gigabyte) for the energy consumption of transmitted mobile data was constructed for the years 2010-2016. In addition, energy consumption related to mobile data transfer is discussed from a life cycle perspective, considering both direct and indirect energy use and challenges in conducting such assessments. Contributions of relevant technological and social developments (radio network technology transformations from $4 \mathrm{G}$ to $5 \mathrm{G}$ and consumer behavior) are analyzed considering possible trade-offs and pointing out aspects that require future studies.
\end{abstract}

\section{Introduction}

Information and communication technology (ICT) is increasingly integrated in all our activities. Developments related to internet of things and digitalization increase the use of ICT almost everywhere. 
Amount of mobile devices such as smart phones is growing globally, leading to an increasing demand for mobile data (Cisco Visual Networking Index, 2017). Fulfilling the demand for mobile data and new services such as high resolution videos and virtual and augmented reality is expected to increase mobile networks' energy consumption (See e.g. Andrae \& Edler, 2015; Katsigiannis \& Hämmäinen, 2014).

In 2016, advanced mobile networks (LTE) reached almost half of the world population, and within the least developed countries, mobile access was on average significantly cheaper compared to fixed broadband access (ITU, 2017). According to UN specialized agency for information and communication technology (ITU), access to ICT and broadband has the potential to serve as a major accelerator for reaching the UN2030 Goals for sustainable development (ITU, 2016). While mobile broadband connections provide great potential for positive sustainability impacts, estimated increase in energy consumption of the mobile networks requires attention.

The aim of the paper is to discuss the importance of mobile access networks when evaluating environmental impacts and sustainability of Internet and electronic services, and give a trend-estimate of electricity intensity of mobile access networks in Finland. The growth of mobile data usage in Finland has been rapid and continuous growth is foreseen. In 2016, average monthly use of mobile data per Finnish in habitant was 16 gigabytes, and mobile data transmission volume exceeded 1 million terabytes (FICORA, 2017b). According to Finnish Communications Regulatory Agency (FICORA), Finns are currently the top users of mobile data in the world. Data consumption in other countries has ranged between 2 to 7 gigabytes per month per capita (FICORA, 2017a). As a consequence, although preliminary, results from Finland could be of interest to other countries, since similar developments with data usage patterns might be expected in the near future.

Life cycle assessment (LCA) studies are important for evaluating the environmental impact of ICT related services. While there are several studies that have evaluated the environmental impacts of ICT and data transfer, to our knowledge, not much information is currently available about the impacts of mobile services and networks. Existing studies (Malmodin \& Lundén, 2016; Malmodin, Lundén, Moberg, Andersson, \& Nilsson, 2014; Scharnhorst, Hilty, \& Jolliet, 2006; Schien, Shabajee, Yearworth, $\&$ Preist, 2013) provide important information and a good starting point. However, due to rapid technical development in both radio network technology and changes in user behavior, existing studies are quickly outdated. For example, the situation in Finland at the moment is very different from the existing studies, due to wide population-coverage of the 4G LTE network in the end of 2016 and high mobile data consumption figures.

Within the paper, our preliminary estimates from the energy intensity of mobile access networks are compared with existing estimates of energy intensity of data transfer (considering mobile and fixed access networks and ICT sector as a whole), in order to identify potential development trends and patterns, and to compare our findings with current literature in the field. The paper focuses on two aspects that have been identified important for tackling the increasing overall energy demand related to mobile data transfer: radio network technology development and user behavior.

\section{Materials and methods}

Life cycle assessment (LCA) considers the environmental impacts of products covering the whole life cycle. Environmental life cycle assessment is a standardized and systematic analytical method by which the potential environmental effects related to ICT goods, networks and services can be estimated. LCAs have a cradle-to-grave scope where all the life cycle stages (raw material acquisition, production, use and end-of-life treatment) are included (ETSI-Standard, 2015). The aim of life cycle thinking is to have a comprehensive understanding of potential environmental impacts and relevant aspects in different life cycle stages and of the interrelations and connections between these phases. 
During the study, available literature describing life cycle environmental impacts related to ICT and electronic services was reviewed. The focus of the review was on LCA studies relevant for mobile data transfer and mobile access networks. In order to have an understanding of electricity consumption related to mobile data transfer in Finland, an estimation of overall energy consumption of the Finnish operators was prepared. Then a $\mathrm{kWh} /$ transferred gigabyte trend was constructed by using a top-down approach in which the estimated operator level total electricity consumption was divided by total data that has been transferred through the network (Schien \& Preist, 2014).

The aim of this study was also to understand the magnitude of telecommunications related electricity consumption when compared to overall electricity consumption in Finland, and to see how the electricity consumption related to networks has developed during the recent years, taking into account the rapid growth in data consumption and the recent investments in 4G LTE network technology.

The overall electricity consumption trend of mobile operators from the beginning of 2010 was estimated based on published corporate data (annual and environmental reports) of three biggest operators covering 99\% market share of mobile subscriptions in Finland during 2017 (FICORA, 2017). Mobile data transmission volume is collected semi-annually by FICORA (Finnish Communications Regulatory Agency). The biggest operator has expressed that the majority of its climate impact results from energy use and the energy consumption of data communications network accounts for approximately 80 per cent of its carbon footprint (Elisa, 2014). According to Han et al. (2011) approximately $57 \%$ of power consumption of a typical wireless cellular network could be allocated to base stations. Applying these two rough defaults and data from corporate reports, an illustrative trend (kWh/gigabyte) for transmitted mobile data was constructed for the years 2010-2016. Both factors are somewhat uncertain and dynamic. However, they were assessed in order to illustrate relative annual trend.

\section{Results}

\subsection{Estimation of mobile operators' energy consumption in Finland}

Our preliminary results based on conducted top-down analysis indicate that the specific electricity consumption per transmitted gigabyte has decreased substantially even if operators' absolute electricity consumption has turned to grow again since 2014. An estimate of the overall energy consumption for all operators in Finland was around 0.6 TWh/a in 2016. This corresponds to 0.7\% of the total annual electricity consumption in Finland in $2016(85.1 \mathrm{TWh} / \mathrm{a})$. The results of the assessment and the development trend for years 2010-2016 are presented in figure 1. 


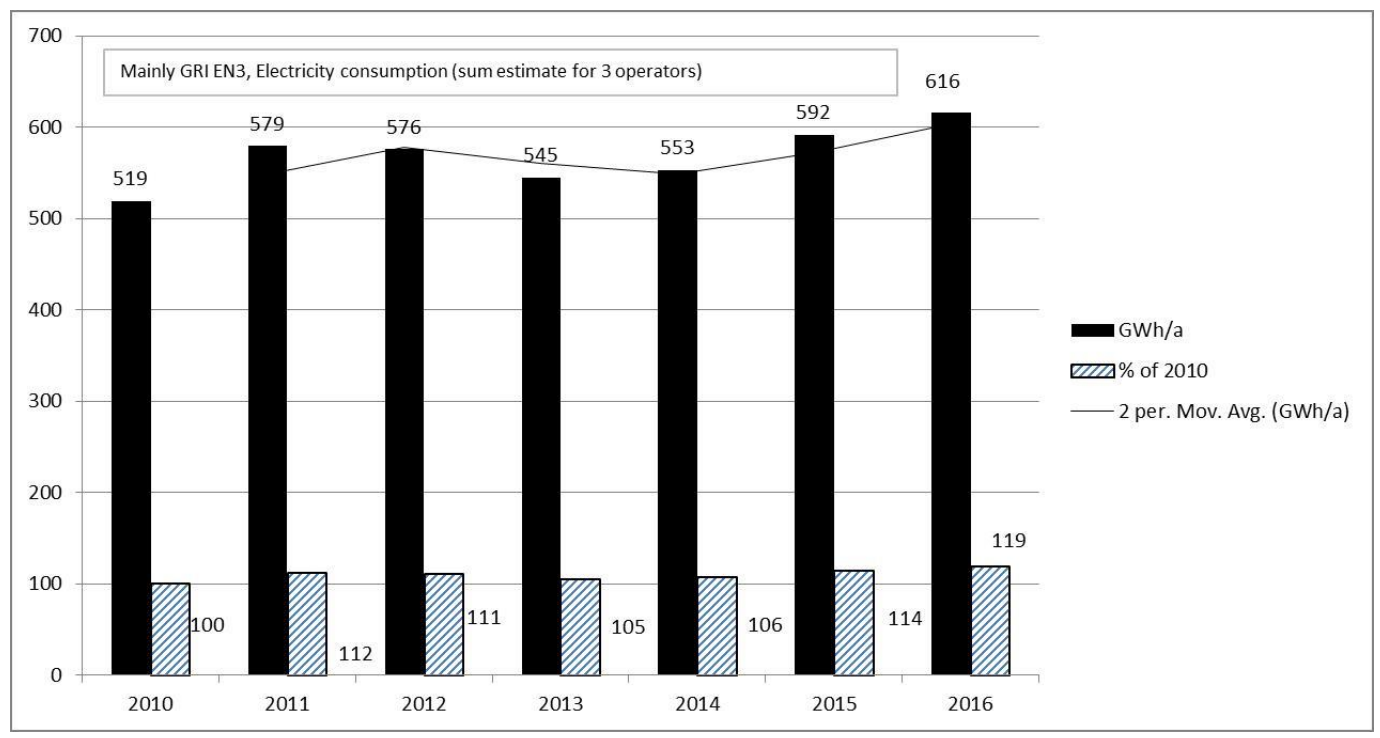

Figure 1 Annual electricity consumption estimate for three main operators' activities in Finland based on various company reports (mainly Global Reporting Initiative GRI EN 3 data from environmental reports). Some uncertainty is relating e.g. to categorization of international activities and grouping of published data. (Mov.Avg.= Moving average)

Based on data published by FICORA (2017) an exponential growth trend for the transmitted mobile data in Finland was constructed (Figure 2.).

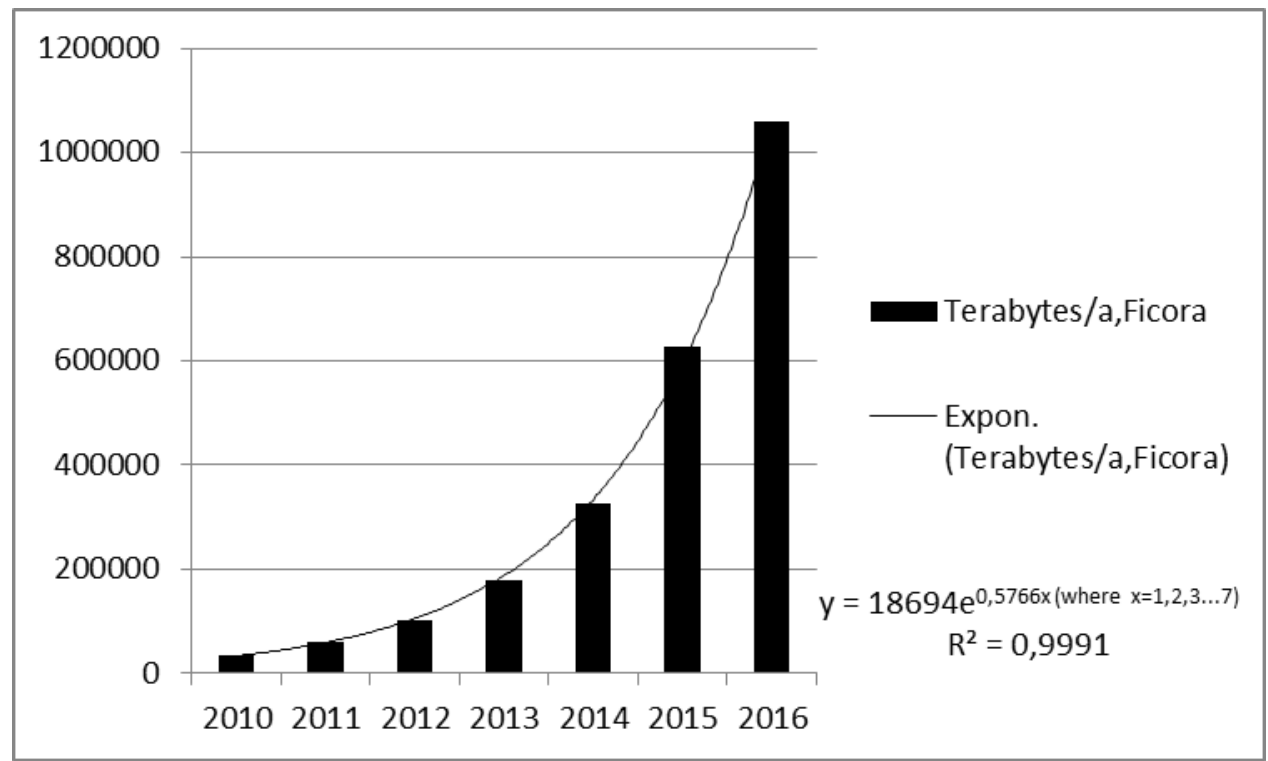

Figure 2 Fig. 2. The transmitted mobile data in Finland during 2010-2016 in terabytes. The volume contains both the traffic the user has sent (uploaded) and the traffic the user has received (downloaded). Source: FICORA 
During the last reported year annual growth rate was still $69 \%$. By combining the overall electricity consumption estimate for production networks ( $80 \%$ of operators overall consumption) with previous estimates of overall data usage, an indicative trend of electricity consumption (kWh) per transferred gigabyte for the years 2010-2016 was created, together with an estimate for the coming years (Figure 3.).

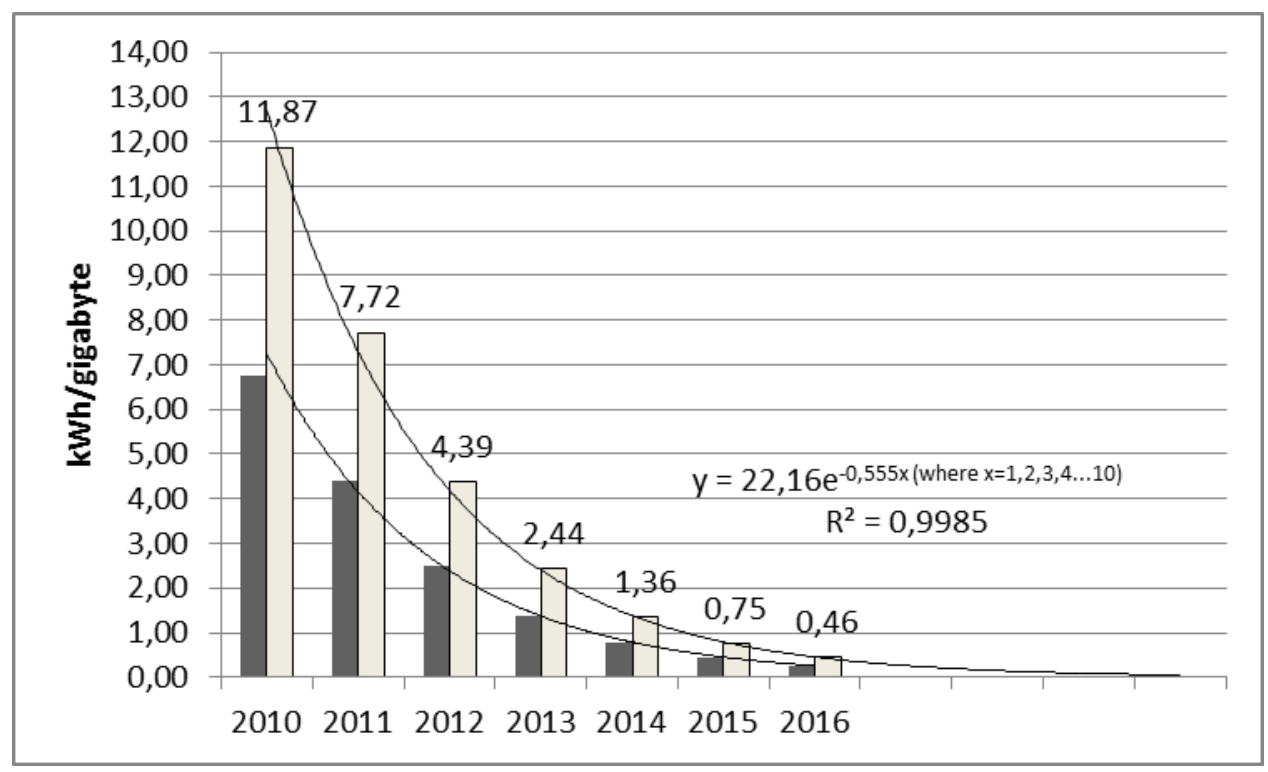

Figure 3 Estimated trend curve for the development of energy efficiency of transmitted mobile data (kWh/gigabyte) in Finland during 2010-2016. The higher development trend is for production networks and lower for base stations only.

Based on data usage and electricity consumption data it can be estimated that during 2016 the specific electricity consumption per one gigabyte decreased below the level $0.5 \mathrm{kWh} /$ gigabyte and is still decreasing when the capacity utilization factor of existing $4 \mathrm{G}$ LTE networks is improving. Based on above mentioned equation the level $0.05 \mathrm{kWh} /$ gigabyte could be achievable around 2020 although annual electricity consumption is expected to increase 1.5 - 2-fold compared to current level. Thus new efficiency improvement measures should be introduced and implemented to restrict and control increasing operational costs of electricity.

The results presented here can be considered as preliminary, and direct comparison with other available studies is not possible. However, a short reflection with available literature is included in order to evaluate the accuracy of our results. Comparison with earlier studies is difficult since due to rather rapid technical development and increase in data consumption, available estimates get quickly outdated. In addition, life cycle based energy consumption figures are often case specific and largely dependent on the assumed network technologies, end-user devices and assumptions related to the use phase.

In previous studies, several estimates about the electricity intensity of Internet data transmission have been presented and thoroughly analyzed (See: Aslan, Mayers, Koomey, \& France, 2017; Schien \& Preist, 2014). Electricity intensity in this context has most often been defined as energy consumed per amount of transmitted data (e.g. Coroama, Hilty, Heiri, \& Horn, 2013) and commonly expressed as a ratio of kilowatt hours per gigabyte $(\mathrm{kWh} / \mathrm{GB})$. While existing studies typically use different approaches and system boundaries, most of the existing estimates consider only fixed-line access networks, and less information about the mobile access networks seems to be available. This is most 
likely due to previously dominating role of fixed access networks in several countries. However, the latest developments related to increasing mobile data usage and wider coverage of advanced mobile network technologies (LTE, 4G) indicate that more information about environmental impacts related to mobile networks and mobile data transfer should be provided in future.

Using data volumes from year 2010 Malmodin and colleagues (2014) estimated electricity consumption per data volume as follows: $0.08 \mathrm{kWh} /$ gigabyte for averaged fixed broadband access network, compared to $2.9 \mathrm{kWh} /$ gigabyte for average $3 \mathrm{G}$ mobile broadband access network and 37 $\mathrm{kWh} /$ gigabyte for average $2 \mathrm{G}$ mobile communication (Malmodin et al., 2014). Within the same study, the energy consumption of data transmission and IP core network was estimated to be 0.08 $\mathrm{kWh} /$ gigabyte. Different from our study, the estimates presented by Malmodin et al. (2014) were prepared using a bottom-up approach, in which the starting point was measured energy consumption of dedicated network devices.

A modelling and scenario study by Andrae and Edler (2015) includes estimates about electricity consumption of fixed and wired access networks together with estimates of global ICT related energy consumption for the years 2010, 2020 and 2030. Their analysis of electricity consumption of fixed and wired access networks and data centers shows that wireless access networks (WAN) are currently considered more energy consuming per kWh/GB compared to fixed access networks (FAN) (See Table $1)$.

Table 1 Electricity Intensity roadmap for networks and data centers in 2010, 2020 and 2030. Total usage normalized by data. (Source: Andrae \& Edler, 2015)

\begin{tabular}{|l|c|c|c|}
\hline & $\begin{array}{c}\mathbf{2 0 1 0} \\
(\boldsymbol{k W h} / \mathbf{G B})\end{array}$ & $\begin{array}{c}\mathbf{2 0 2 0} \\
(\boldsymbol{k W h} / \mathbf{G B})\end{array}$ & $\begin{array}{c}\mathbf{2 0 3 0} \\
(\boldsymbol{k W h} / \boldsymbol{G B})\end{array}$ \\
\hline FAN wired & 0.50 & $0.11-0.28$ & $0.061-0.17$ \\
\hline FAN Wi-Fi & 0.36 & $0.07-0.17$ & $0.014-0.10$ \\
\hline WAN & $\mathbf{6 - 1 5}$ & $\mathbf{0 . 0 4 7 - 1 . 0 4}$ & $\mathbf{0 . 0 0 2 - 0 . 0 4 8}$ \\
\hline Data centers & $0.13-0.14$ & $0.027-0.085$ & $0.014-0.051$ \\
\hline
\end{tabular}

However, in future, due to increasing data use and improved efficiency of the radio network technologies, the situation should change by year 2030, when $5 \mathrm{G}$ network technologies should be dominating. In order to reach this goal, and in order to keep the total electricity consumption of mobile data networks at a reasonable level, an energy efficiency improvement of more than 99 percent per $\mathrm{kWh} / \mathrm{GB}$ for the WAN is required (Andrae \& Edler, 2015). The estimates presented in Table 1 are quite close to our findings.

\subsection{Energy consumption trends related radio network technologies (mobile access networks)}

Energy efficiency in wireless communications is usually defined as the number of successfully received bits divided by the energy consumed for transmitting and receiving those bits. Alternative definition is the throughput divided by the consumed power, which also results in the same bit/J quantity. (Note that these definitions are different from the ones used in the previous section where focus was more on consumed energy than transmitted bits.) For the earlier mobile access generations until 4G, there have not been any requirements for energy efficiency. However, the energy efficiency has been constantly improving mostly due to the considerable cell throughput improvements. This behavior is visible also in the Finnish national level as seen in Figure 3.

More recently for $5 \mathrm{G}$ systems, network energy efficiency has been defined as one of the main requirements targeting 100-fold improvement over the 4G systems (ITU-R M.2083, 2015). The same 
requirements also define that the area traffic capacity (bit/s/m2) should improve by a factor of 100 . From these requirements, it can be concluded that the power consumption of the $5 \mathrm{G}$ network should remain at the same level as the current $4 \mathrm{G}$ network power consumption. Very roughly speaking, if the traffic volume in 5G networks will be more than 100-times of the traffic volume in $4 \mathrm{G}$ networks, it is expected that the power consumption in the future mobile access networks will increase.

However as seen in Figure 1, the trend in the mobile access network power consumption in Finland is growing (at least temporarily). The background for this trend is that the traffic volume is increasing rapidly (FICORA, 2017) driven by the flat rate pricing strategy of the Finnish operators. Currently, there are three operational mobile access network generations: 2G/GSM, 3G/UMTS, and 4G/LTE. As the $4 \mathrm{G}$ coverage is almost nationwide and the penetration of $4 \mathrm{G}$ smart phones and mobile routers is increasing, the traffic volume is shifting from $3 \mathrm{G}$ to $4 \mathrm{G}$ networks. This has forced the operators to add more capacity and install more $4 \mathrm{G}$ equipment to fulfil the data rate expectations of their customers, which in turn increases the energy consumption. On the other hand, even though the traffic volumes of the legacy $2 \mathrm{G}$ and $3 \mathrm{G}$ networks are decreasing, they still consume significant amount of power. For example according to EU Code of Conduct for network equipment, $2 \mathrm{G}$ and $3 \mathrm{G}$ base stations consume approx. $70 \%$ of the busy hour power when they are at the low-load-state (JRC, 2016). Finnish operators have not yet published any schedules for closing down their $2 \mathrm{G}$ and $3 \mathrm{G}$ networks, which would obviously bring power consumption savings. Currently, the penetration of voice-over-LTE (VoLTE) service over $4 \mathrm{G}$ networks is low, which keeps the $2 \mathrm{G}$ or $3 \mathrm{G}$ coverage mandatory in order to make conventional phone calls. Another reason for maintaining legacy mobile access networks is that many machine-to-machine (M2M) mobile data subscriptions are still based on $2 \mathrm{G}$ connection. However, this is expected to change in the coming years as LTE IoT extensions narrowband-IoT (NB-IoT) and CatM becomes operational (Ericsson, 2016).

5G networks will introduce several new concepts, which will have a clear impact on the power consumption and energy efficiency in the mobile access. A conceptual illustration of the mobile access in the 5G networks is shown in Figure 4 (Figure adapted from Mämmelä, 2015). Massive multipleinput multiple-output (MIMO) (Marzetta, 2010) has been proposed to improve the area traffic capacity and spectral efficiency (Boccardi, Heath, Lozano, Marzetta, \& Popovski, 2014). In massive MIMO, a large number of antennas are used to serve a set of single-antenna user equipments (UEs) over the same physical resource blocks. When the number of antennas is much larger than the number of UEs, the signal quality for the UEs can be clearly improved and the transmitted power can be reduced. It is expected that massive MIMO should provide energy efficiency gain over conventional 4G base stations mostly due to the possibility to use low-power RF components (Desset, Debaillie, \& Louagie, 2014). Increasing the number of antennas not only increases the cell throughput but also highly increases the circuit power consumption. Thus for a given number of UEs, there is an energy efficiency-optimal number of antennas to be used for transmission and reception (Björnson et al., 2015). If a massive MIMO base station is able to adapt its number of active antennas to the number of served UEs, significant energy efficiency gain can be achieved (Apilo, Lasanen, \& Mammela, 2016; Hossain, Jantti, \& Cavdar, 2014). 


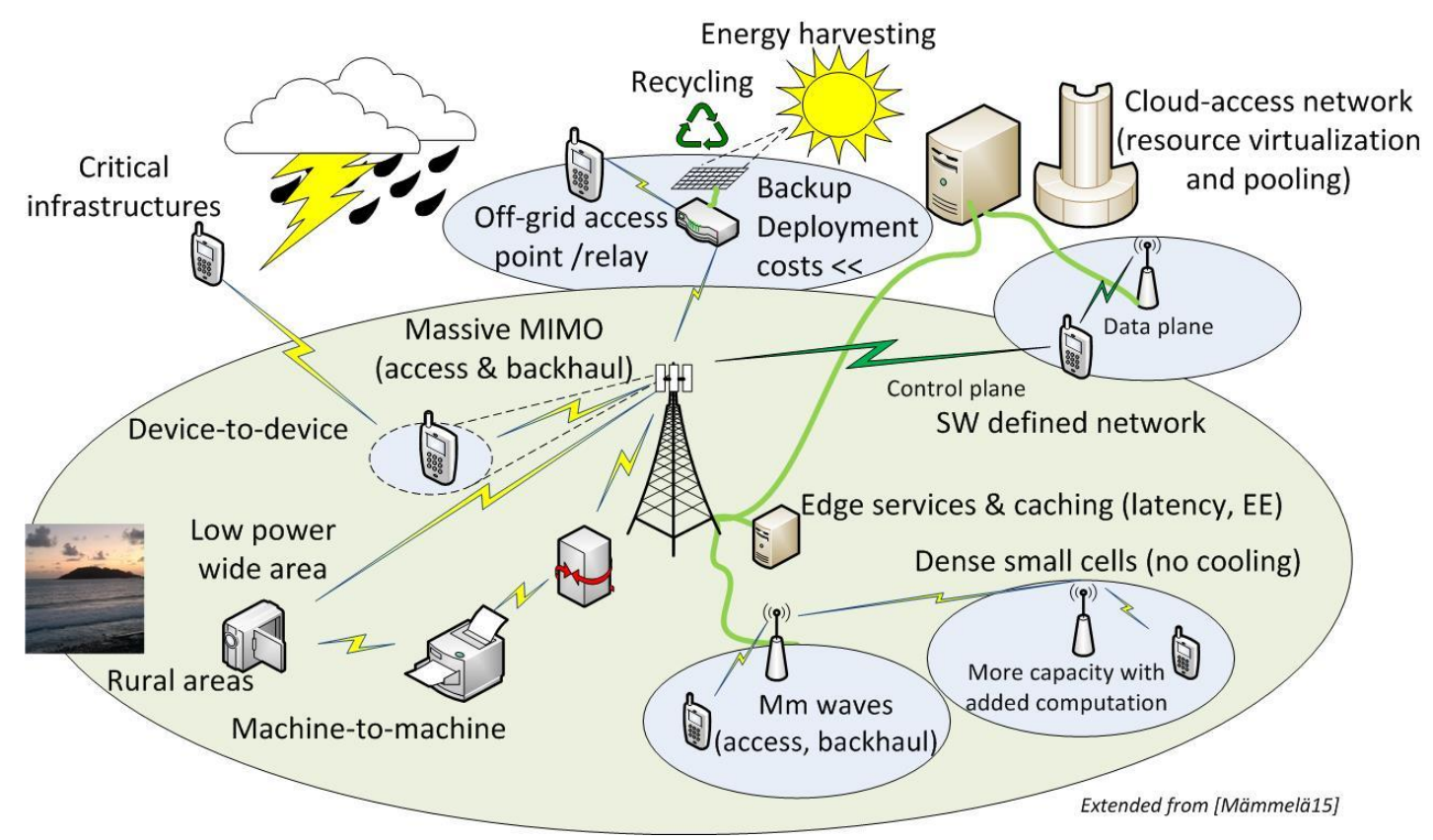

Figure $45 \mathrm{G}$ techniques having a clear impact on the energy efficiency. (Source: Mämmelä 2015)

Dense network consisting of small cells is an essential concept in $5 \mathrm{G}$ to reach the ambitious ubiquitous user experienced data rate targets (ITU-R M.2083, 2015). Small cells can potentially also significantly improve the energy efficiency, especially when sleep modes are enabled during low or no traffic (Liu, Han, \& Yang, 2014). An efficient way to enable deep sleep modes of small cells is so called dual connectivity where large macro cells and overlapping small cells provide control and data plane services, correspondingly (Xu, He, Zhang, Chen, \& Xu, 2013). In this case, small cells can be safely put into deep sleep mode when they are not serving any UEs because the macro cell provides downlink broadcast signaling that enables UEs to connect to the network.

Millimeter wave access is a key to reach really high data rates in small cells by the use of very wide bandwidths (up to 1-2 GHz). Massive MIMO has the potential to fit very well for millimeter wave communications. The shorter wavelengths at higher frequencies reduce the sizes of large antenna arrays to be more practical. Additionally, the high beamforming gain of massive MIMO can partially compensate the increased path losses from millimeter wave propagation ( $\mathrm{Lu}$, Member, Li, \& Swindlehurst, 2014). However, even if the energy efficiency with millimeter wave transmitter is expected to improve, the power consumption in the RF circuits increases without careful design. This can be explained by the increased power consumption in the RF circuits, which is dominated by the maximum operational frequency (Swindlehurst, Ayanoglu, Heydari, \& Capolino, 2014). Cloud-access network architecture has been proposed for $5 \mathrm{G}$ in order to improve scalability and resource efficiency. In a cloud-access network, a baseband unit pool is shared among a large number of cells. This improves the utilization rate of processing resources and decreases cooling power consumption by cutting down the number of site equipment shelters needing air conditioning ( $\mathrm{Wu}, \mathrm{Yang}, \mathrm{Li}, \& \mathrm{Li}, 2015$ ). In addition, the centralized control of remote radio units makes it easier to implement cell sleep modes and shaping according to geographical traffic fluctuations (Buzzi et al., 2016).

In general, mobile communication evolution is going from transmission power domination to computing power intense operation as communication distances are becoming shorter. Related 
challenges need to be considered carefully both at the base station (Ge, Yang, Gharavi, \& Sun, 2017) and mobile terminal side (Mämmelä \& Anttonen, 2017).

\subsection{Role of mobile access networks in the value chain of electronic services}

Traditionally, end-user devices have been among the biggest contributors when considering life cycle energy demand and carbon footprint in the ICT chain (Malmodin et al., 2014). Due to improved energy-efficiency of TV's, tablets, computers and mobile phones and increasing data usage, the burden seems to be moving from device use towards networks and data centers (Andrae \& Edler, 2015; Hischier, Coroama, Schien, \& Achachlouei, 2015).

Within the service or device specific studies, the role of network energy consumption has often been difficult to evaluate due to lack of generalized data related to energy consumption of the network and its different parts. Available estimates of energy intensity of the Internet have differed at most by a factor of more than 20,000, ranging from $136 \mathrm{kWh} /$ gigabyte to $0.0064 \mathrm{kWh} /$ gigabyte (Coroama, Schien, Preist, \& Hilty, 2015). A large variety within the results has been explained by differences in system boundaries, applied assumptions and year to which the data applies (Aslan et al., 2017).

Quick, generalized assessments including network operations are challenging also from methodological point of view, since energy consumption scales differently in different parts of the network. Energy consumption of the fixed access network, customer premises equipment (CPE) and end-user devices usually scales with time of usage, being largely traffic-independent. However, most of the networking devices within the metro and core networks scale with traffic volumes. (Coroama et al., 2015) When mobile access networks are considered, traffic load should be considered, since energy consumption is partly dependent from the traffic, even though the idle energy consumption (without data traffic) is also significant.

Within their study about the energy and carbon footprints of the entertainment and media sector in Sweden in 2015, Malmodin \& Lunden (2016) point out that the biggest contributors to the electricity consumption are TV's and TV peripherals, followed by data rooms/centers, PCs and tablets, access networks being the fourth place, very close to phones and CPE (Malmodin \& Lundén, 2016). However, when comparing to similar results from 2010, the biggest decrease has occurred within electricity consumption of PC's and tablets (-35\%), while the biggest increase has occurred within access networks $(+20 \%)$. In this figure, both fixed and mobile access networks are included, however, increase in mobile network energy consumption was $150 \mathrm{GWh}$, while the increase in fixed access networks was $45 \mathrm{GWh}$ in five years (Malmodin \& Lundén, 2016).

In an earlier LCA study using measured information for different network operations, Malmodin and colleagues (Malmodin et al., 2014) conclude that the biggest contribution to ICT related carbon footprints comes from the end-user devices (especially personal computers), and that the parts closest to the consumer seem to be responsible for majority of the impact. The energy consumption of customer premises equipment at people's homes was more than the consumption of fixed access and mobile access networks all together. However, since the data for the study originates from year 2010, the consumption figures for mobile data have been on a lower level compared to 2016.

When evaluating the energy footprint of various combinations of user devices and access networks, Schien and colleagues (2013) found out that differences between various combinations of devices and networks may be very significant. However, their findings also point out that downloading video content using a mobile phone in $3 \mathrm{G}$ network causes significant energy consumption particularly within the mobile access network, while the impacts on other parts of the value chain are minor. Other significant sources of the energy footprint within their study were user devices and data centers (Schien et al., 2013). However, their findings highlight the importance of considering the environmental impacts of mobile networks in future studies. The results received from our study in Finland underline the 
importance of this finding, since increasing use of video content seems to be a major cause for the increase in the energy consumption of mobile network operators.

An LCA study of $2 \mathrm{G}$ and $3 \mathrm{G}$ networks (including the manufacturing, use and end-of-life phases) indicated that use phase (operation of the network) accounts for the biggest parts of the environmental impacts of the networks, compared to production and end-of-life phases (Scharnhorst et al., 2006). In addition, parallel operation of GSM (2G) and UMTS (3G) networks should be kept as short as possible, in order to reduce the environmental impacts related to operation of both networks (Scharnhorst et al., 2006). While the data applied in this study can be considered at least partly outdated, it should be noted that parallel operation of network technologies seems to be a common practice for the mobile operators, increasing the energy consumption related to the networks. As a consequence, within a cell or site, several technologies are commonly included $(2 \mathrm{G}, 3 \mathrm{G}, 4 \mathrm{G})$, as older equipment is not always removed or replaced when new generation equipment is being installed. Energy savings are finally achieved when oldest equipment is gradually removed. (See also chapter 3.2 and Malmodin \& Lundén, 2016).

\subsection{Impact of user behavior on overall energy consumption}

In their review of direct and indirect energy effects of ICT, Horner et al. (2016) conclude that despite of several studies conducted over the last decades, the overall net effect of ICT adoption remain unclear. When considering different electronic/ICT services, a meta-analysis of the studies points out that in principle, ICT has a large energy savings potential, but realization of that potential is not assured. One of the reasons for this uncertainty is that lack of empirical data on how human users interact with ICT systems hinders the ability to assess actual energy effects. (Horner et al., 2016)

In this paper, the energy consumption of mobile access networks and ICT in general has been discussed. Several LCA studies have revealed that the energy consumption taking place during the use phase of different electronic devices is among the biggest contributors to the overall energy consumption, and often more important compared to consumption of the Internet or the access networks (Coroama et al., 2015; Malmodin et al., 2014). However, the differences between different devices and assumed user habits may be significant. With new energy efficient mobile devices, production of the device might be more significant source of environmental impacts, when compared to use phase (Hischier et al., 2015). Other studies have pointed out that energy consumption of the mobile access network becomes significant when video content is downloaded using mobile devices (Schien et al., 2013). The development taking place in Finland indicates that increasing use of mobile devices and especially the video content is increasing the total energy consumption related to mobile networks, even though the normalized $\mathrm{kWh} /$ Gigabyte consumption is simultaneously decreasing.

The increasing trend related to mobile networks energy consumption has been recognized also by the authorities and technology developers. As discussed in chapter 3.2, energy efficiency is one of the starting points for the development of the future 5G network technologies. Possible inclusion of home network equipment, smart phones and base stations within the Ecodesign working plan is currently under study, with the overall aim to determine the best policy approach for improving their energy efficiency and wider circular economy aspects (European Commission, 2016). In Finland, 5G networks are currently in the testing phase and reliable estimates of energy consumption of the 5G networks and related user services can be foreseen in future.

However, even if the energy efficient user devices are decreasing the direct energy consumption originating from the use phase, the importance of environmentally conscious user behavior should be highlighted in future, and dedicated studies and guidelines for consumer information purposes should be created. For the moment, consumption of electronic services is rarely considered as consumption with potential environmental impacts (Federley, Nors, Pihkola \& Behm, 2014).

Recent studies have pointed out that increasing consumption (more devices and longer hours of use together) might have already exceeded both energy and resource savings achieved due to more energy efficient consumer electronics (Hischier \& Wäger, 2015). In addition, other important aspects related 
to environmental impacts of ICT or electronic devices (either using mobile or fixed access networks) are the lifetime of the products and benefits achieved from recycling.

Currently, one of the most efficient and simple means of reducing environmental impacts of ICT and related electronic devices is to use the same device longer and after the use phase to use make sure that the device ends-up in an dedicated recycling scheme. However, even though the solution sounds simple, acting according to this advice might not be possible, no matter how environmentally conscious consumers we would like to be. Low price of the devices, combined with limited possibilities for repair and fast technology development rather encourage us for regularly buying a new device. It might even be a necessity, when user interfaces or software packages included in old devices become outdated, or if no repair services exist. Similarly, cheap and efficient mobile connections allow downloading more and more contents from the network, increasing the total energy consumption (and without the consumer even realizing it).

Although the total environmental impacts of digital services may still be relatively small compared to housing, transport and food (which are the major causes of climate impacts from households in Finland (Seppälä et al., 2011)), increasing use of ICT is quickly changing our consumption habits, possibly leading to unsustainable practices (see e.g. Bates et al., 2015). In order to avoid increasing the negative impacts, we perhaps should start thinking about electronic consumption as consumption with physical impacts and consequences. However, this requires that much more information on environmental impacts of electronic devices and services would become available.

In addition to energy consumption, increasing public awareness of the importance of recycling of electronic devices is one of the topics that requires urgent actions. While benefits from recycling are often considered within the LCA studies evaluating environmental impacts of ICT, challenges within the recycling of waste electronics equipment (WEEE) are topic of increasing concern in Europe and globally. Currently, out of 9 million tons of WEEE created annually, only 3 million tons are properly recycled. (For more information about challenges related to WEEE recycling, see e.g IVL Swedish Environmental Research Agency, 2017). As a consequence, many of the potential benefits related to recyclability of the devices are not achieved. On the contrary, severe environmental and social consequences have occurred.

\section{Conclusions and discussion}

Our findings point out that although the energy efficiency of mobile access networks has significantly improved during the last 5 years, it seems that the total energy consumption is growing due to increasing data usage and new functionalities. This finding is similar with the existing studies that have predicted increase in total energy consumption related to ICT in future (See Andrae \& Edler, 2015; Hintemann \& Clause, 2016). Our findings are still preliminary in nature and require further studies, more profound time series and longer periods. Based on our results it seems that the development in Finland does not yet confirm the conclusions presented by Malmodin \& Lunden (2016), who predict a declining trend in the energy and carbon footprints of the ICT and Entertainment \& Media sectors in Sweden, despite continuous growth in data traffic (Malmodin \& Lundén, 2016) . However, it is important to note that scope and approach of the studies has been very different.

Currently, there is a lack of publicly available data for making reliable judgements of the energy intensity, emissions and various environmental impacts of mobile services in Finland. Although our energy efficiency trend-estimate is preliminary in nature and contains uncertainty, we hope that it provides a starting point for preparing more accurate estimates for specific systems in the future. In addition, an indicative comparison with existing literature points out that our findings are somewhat in line with previous estimates. To gain a more detailed estimation of energy consumed by the mobile 
networks and mobile data, a bottom-up study based on measured energy consumption of the different network components should be conducted.

In future, more accurate estimates (covering the whole life cycle of various ICT services) would be helpful to actors working within the telecommunications sector for making product-based assessments and for evaluating the impacts of their own products and services on the overall energy consumption. This information would also be important for informing consumers about the environmental impacts of the increasing consumption of electronic services and mobile data. Due to importance of the use phase for determining the overall environmental impact related to mobile and electronic services, informing consumers about environmentally friendly use habits could be one of the means for tackling increasing energy demand in future, in addition to more energy efficient devices and networks. However, this would require that transparent and comprehensive data on the impacts of user behavior would be easily available.

From life cycle point of view, although comparing different technologies is challenging, accessing the Internet via mobile networks currently consumes more energy compared to fixed access networks. Considering the growing number of mobile devices and increasing coverage of advanced mobile networks (LTE, 4G), mobile access networks should be included in future studies, when making estimations about the energy intensity of electronic services. If possible, generic models allowing quick estimates of energy consumption should be built, taking into account the specific features related to mobile access networks, and the characteristics of the local network structure.

Energy efficiency has been one of the starting points for the development of new $5 \mathrm{G}$ radio technology. However, massive increase in data usage might challenge achieving the energy efficiency goal. Energy sufficiency strategies should be considered especially in the developing countries, where solar energy could play an increasing role in future. Although a significant decrease in the $\mathrm{kWh} /$ gigabyte consumption can be predicted, an increase in total energy consumption can be foreseen.

In order to keep ICT related energy consumption at a moderate level in future, despite of exponential growth in data usage and more data intensive services, attention should be paid to both direct and indirect energy consumption during different life cycle phases. Future assessments should take into account consumers, service providers, mobile operators and technology and system developers alike, and not forgetting materials recycling, various renewable energy options, energy recovery and cooling technologies either. Especially, we should aim to inform different actors on their possibilities to reduce the overall environmental impacts related to ICT, as these impacts are not easily discovered by the persons either designing or using mobile services.

\section{References}

Andrae, A., \& Edler, T. (2015). On Global Electricity Usage of Communication Technology: Trends to 2030. Challenges, 6(1), 117-157. https://doi.org/10.3390/challe6010117

Apilo, O., Lasanen, M., \& Mammela, A. (2016). Unequal power amplifier dimensioning for adaptive massive MIMO base stations. IEEE Vehicular Technology Conference, 2016-July. https://doi.org/10.1109/VTCSpring.2016.7504517

Aslan, J., Mayers, K., Koomey, J. G., \& France, C. (2017). Electricity Intensity of Internet Data Transmission: Untangling the Estimates. Journal of Industrial Ecology, O(0), 1-14. https://doi.org/10.1111/jiec.12630

Bates, O., Lord, C., Knowles, B., Friday, A., Clear, A., \& Hazas, M. (2015). Exploring (un)sustainable growth of digital technologies in the home. In Proceedings of the Third International Conference on ICT for Sustainability (ICT4S). Atlantis Press.

Björnson, E., Sanguinetti, L., Hoydis, J., Debbah, M., Björnson, E., Sanguinetti, L., ... Design, O. 
(2015). Optimal Design of Energy-Efficient Multi-User MIMO Systems : Is Massive MIMO the Answer? To cite this version : HAL Id : hal-01242459 Optimal Design of Energy-Efficient MultiUser MIMO Systems : Is Massive MIMO the Answer?, 14(6), 3059-3075.

Boccardi, F., Heath, R., Lozano, A., Marzetta, T. L., \& Popovski, P. (2014). Five disruptive technology directions for 5G. IEEE Communications Magazine, 52(2), 74-80. https://doi.org/10.1109/MCOM.2014.6736746

Buzzi, S., Chih-Lin, I., Klein, T. E., Poor, H. V., Yang, C., \& Zappone, A. (2016). A survey of energyefficient techniques for $5 \mathrm{G}$ networks and challenges ahead. IEEE Journal on Selected Areas in Communications, 34(4), 697-709. https://doi.org/10.1109/JSAC.2016.2550338

Cisco Visual Networking Index. (2017). Global Mobile Data Traffic Forecast Update, 2016-2021 White Paper.

Coroama, V. C., Hilty, L. M., Heiri, E., \& Horn, F. M. (2013). The direct energy demand of internet data flows. Journal of Industrial Ecology, 17(5), 680-688. https://doi.org/10.1111/jiec.12048

Coroama, V. C., Schien, D., Preist, C., \& Hilty, L. M. (2015). The energy intensity of the internet: Home and access networks. Advances in Intelligent Systems and Computing, 310, 137-155. https://doi.org/10.1007/978-3-319-09228-7_8

Desset, C., Debaillie, B., \& Louagie, F. (2014). Modeling the hardware power consumption of large scale antenna systems. 2014 IEEE Online Conference on Green Communications, OnlineGreenComm 2014, 1-6. https://doi.org/10.1109/OnlineGreenCom.2014.7114430

Elisa. (2014). Annual Report and Corporate Responsibility Report 2014. Retrieved from http://www.elisa.com/attachment/content/Elisa_Annual_Report_2014.pdf

Ericsson. (2016). Mobility Report. White Paper, (May), 7-8. https://doi.org/10.3103/S0005105510050031

ETSI-Standard. (2015). Methodology for Environmental Life Cycle Assessment (LCA) of Information and Communication Technology (ICT) goods, networks and services, ETSI ES 203 199 V1.3.1 (2015-02). ETSI-Standard, Environmental Engineering.

European Commission. (2016). Ecodesign working plan 2016-2019 COM(2016) 773 final. European Commission. Retrieved from https://ec.europa.eu/energy/sites/ener/files/documents/com_2016_773.en_.pdf

Federley, Maija; Nors, Minna; Pihkola, Hanna; Behm, K. (2014). End-user perspectives on environmental sustainability and communication - Case study on media use. In 2nd International Conference on ICT for Sustainability. Book of abstracts. KTH Royal Institute of Technology; VU University Amsterdam.

FICORA. (2017). Ficora statistics 2017, market shares of mobile subscriptions. Retrieved from https://www.viestintavirasto.fi/en/statisticsandreports/statistics/2013/marketsharesofmobilesubs criptions.html

FICORA. (2017). Statistics service 2017, industry information. Retrieved from https://www.viestintavirasto.fi/attachments/toimialatieto/NBS_publication_2016.pdf

FICORA. (2017). Statistics service 2017, mobile data transmission volume. Retrieved from https://www.viestintavirasto.fi/en/statisticsandreports/statistics/2013/mobiledatatransmissionvol ume.html

Ge, X., Yang, J., Gharavi, H., \& Sun, Y. (2017). Energy Efficiency Challenges of 5G Small Cell Networks. IEEE Communications Magazine, 55(5), 184-191. https://doi.org/10.1109/MCOM.2017.1600788

Han, C., Harrold, T., Armour, S., Krikidis, I., Videv, S., Grant, P. M., ... Hanzo, L. (2011). Green radio: Radio techniques to enable energy-efficient wireless networks. IEEE Communications Magazine, 49(6), 46-54. https://doi.org/10.1109/MCOM.2011.5783984

Hintemann, R; Clause, J. (2016). Green Cloud? The current and future development of energy consumption by data centers, networks and end-user devices. In Proceedings of the ICT for Sustainability 2016. Advances in Computer Science Research. Retrieved from 
https://www.atlantis-press.com/proceedings/ict4s-16/25860373.

Hischier, R., Coroama, V. C., Schien, D., \& Achachlouei, M. A. (2015). Grey energy and environmental impacts of ICT hardware. Advances in Intelligent Systems and Computing, 310, 171-189. https://doi.org/10.1007/978-3-319-09228-7_10

Hischier, R., \& Wäger, P. A. (2015). The transition from desktop computers to tablets: A model for increasing resource efficiency? Advances in Intelligent Systems and Computing, 310, 243-256. https://doi.org/10.1007/978-3-319-09228-7_14

Horner, N. C., Shehabi, A., \& Azevedo, I. L. (2016). Known unknowns: indirect energy effects of information and communication technology. Environmental Research Letters, 11(10), 103001. https://doi.org/10.1088/1748-9326/11/10/103001

Hossain, M. M. A., Jantti, R., \& Cavdar, C. (2014). Dimensioning of PA for massive MIMO system with load adaptive number of antennas. 2014 IEEE Globecom Workshops, GC Wkshps 2014, 1102-1108. https://doi.org/10.1109/GLOCOMW.2014.7063580

ITU. (2016). Facts and figures 2016. Retrieved from https://www.itu.int/en/ITUD/Statistics/Documents/facts/ICTFactsFigures2016.pdf

ITU. (2017). Facts and Figures 2017. Retrieved from https://www.itu.int/en/ITUD/Statistics/Documents/facts/ICTFactsFigures2017.pdf.

IVL Swedish Environmental Research Agency. (2017). Unleashing the power of secondary materials: A strategic research and innovation agenda for effective material recycling from ELV, WEEE and plastic packaging waste streams. D5.3 of the NewInnonet project. Retrieved from http://www.newinnonet.eu/downloads/D 5.3. Final Integrated Strategic Innovation and Research agenda .pdf.

JRC. (2016). EU Code of Conduct on energy consumption of broadband equipment, JRC Technical report version 6.

Katsigiannis, M., \& Hämmäinen, H. (2014). Energy consumption of radio access networks in Finland. Telecommunication Systems, 55(2), 241-251. https://doi.org/10.1007/s11235-013-9778-y

Liu, W., Han, S., \& Yang, C. (2014). Energy efficiency comparison of massive MIMO and small cell network. 2014 IEEE Global Conference on Signal and Information Processing (GlobalSIP), 617 621. https://doi.org/10.1109/GlobalSIP.2014.7032191

Lu, L., Member, S., Li, G. Y., \& Swindlehurst, A. L. (2014). An Overview of Massive MIMO : Bene fi ts and Challenges. Ieee Journal of Selected Topics in Signal Processing, 8(5), 742-758. https://doi.org/10.1109/JSTSP.2014.2317671

Malmodin, J., \& Lundén, D. (2016). The energy and carbon footprint of the ICT and E\&M sector in Sweden 1990-2015 and beyond. Proceedings of the ICT4Sustainability Conference, (Ict4s), 209218.

Malmodin, J., Lundén, D., Moberg, Å., Andersson, G., \& Nilsson, M. (2014). Life Cycle Assessment of ICT: Carbon Footprint and Operational Electricity Use from the Operator, National, and Subscriber Perspective in Sweden Malmodin et al. LCA of ICT Networks from the Operator, National, and Subscriber Perspective. Journal of Industrial Ecology, 18(6), 829-845. https://doi.org/10.1111/jiec. 12145

Marzetta, T. L. (2010). Noncooperative cellular wireless with unlimited numbers of base station antennas. IEEE Transactions on Wireless Communications, 9(11), 3590-3600. https://doi.org/10.1109/TWC.2010.092810.091092

Mämmelä, A. (2015). Energy efficiency in 5G mobile networks. In Networking 2015 conference. Toulouse, France.

Mämmelä, A., \& Anttonen, A. (2017). Why Will Computing Power Need Particular Attention in Future Wireless Devices? IEEE Circuits and Systems Magazined Systems, (First Quarter), 12-26.

Report ITU-R M.2083. (2015). IMT Vision - Framework and overall objectives of the future development of IMT for 2020 and beyond, 0,21 . Retrieved from https://www.itu.int/dms_pubrec/itu-r/rec/m/R-REC-M.2083-0-201509-I!!PDF-E.pdf 
Scharnhorst, W., Hilty, L. M., \& Jolliet, O. (2006). Life cycle assessment of second generation (2G) and third generation (3G) mobile phone networks. Environment International, 32(5), 656-675. https://doi.org/10.1016/j.envint.2006.03.001

Schien, D., \& Preist, C. (2014). Approaches to energy intensity of the internet. IEEE Communications Magazine, 52(11), 130-137. https://doi.org/10.1109/MCOM.2014.6957153

Schien, D., Shabajee, P., Yearworth, M., \& Preist, C. (2013). Modeling and assessing variability in energy consumption during the use stage of online multimedia services. Journal of Industrial Ecology, 17(6), 800-813. https://doi.org/10.1111/jiec.12065

Seppälä, J., Mäenpää, I., Koskela, S., Mattila, T., Nissinen, A., Katajajuuri, J. M., ... Virtanen, Y. (2011). An assessment of greenhouse gas emissions and material flows caused by the Finnish economy using the ENVIMAT model. Journal of Cleaner Production, 19(16), 1833-1841. https://doi.org/10.1016/j.jclepro.2011.04.021

Swindlehurst, A. L., Ayanoglu, E., Heydari, P., \& Capolino, F. (2014). Millimeter-wave massive MIMO: the next wireless revolution? IEEE Communications Magazine, 52(9), 56-62. https://doi.org/10.1109/MCOM.2014.6894453

Wu, G., Yang, C., Li, S., \& Li, G. Y. (2015). Recent advances in energy-efficient networks and their application in 5G systems. IEEE Wireless Communications, 22(2), 145-151. https://doi.org/10.1109/MWC.2015.7096297

Xu, X., He, G., Zhang, S., Chen, Y., \& Xu, S. (2013). On functionality separation for green mobile networks: Concept study over LTE. IEEE Communications Magazine, 51(5), 82-90. https://doi.org/10.1109/MCOM.2013.6515050 